\title{
Determination of Airways Resistance, Volumetric Efficiency and Development of Ventilation Model of Rosh Pinah Zinc Mine Namibia
}

\author{
Jeremia Kalenga, Jide Muili Akande \\ Department of Mining and Metallurgical Engineering, University of Namibia, Ongwediva, Namibia \\ Email: j8kalenga@gmail.com, jakande@unam.na
}

How to cite this paper: Kalenga, J. and Akande, J.M. (2021) Determination of Airways Resistance, Volumetric Efficiency and Development of Ventilation Model of Rosh Pinah Zinc Mine Namibia. Journal of Minerals and Materials Characterization and Engineering, 9, 194-205.

https://doi.org/10.4236/jmmce.2021.92014

Received: November 25, 2020

Accepted: March 22, 2021

Published: March 25, 2021

Copyright $\odot 2021$ by author(s) and Scientific Research Publishing Inc. This work is licensed under the Creative Commons Attribution International License (CC BY 4.0).

http://creativecommons.org/licenses/by/4.0/

\begin{abstract}
A quantitative technique was conducted at Rosh Pinah Zinc mine, Namibia with its main purpose to determine airways resistance which is a function of the parameters; roughness of the airways and the friction factor. The 32 branch points (i.e. a-ag) that stand for ventilation circuit have been selected. Data collected includes, length and width of airways, air velocity; air density, and roughness of the airways which were used to determine coefficient of frictions, friction factors and airway resistances. A ventilation model was developed. In order to improve the current ventilation model, airways resistance of the mine was determined and simulated in a modified model using VentSim ${ }^{\mathrm{TM}}$ software. An average total airways resistance of $0.32027 \mathrm{Ns}^{2} / \mathrm{m}^{8}$ has been achieved for Rosh Pinah mine. It should be pointed out that, as the mine advances its production faces deeper, this value would increases suddenly. Simulation revealed that as much as $34.4 \mathrm{~m}^{3} / \mathrm{s}$ of air can be received at the production faces, compared to the measured received amount of $19.3 \mathrm{~m}^{3} / \mathrm{s}$. Therefore, volumetric efficiency of the mine was improved from $29.3 \%$ to $68.3 \%$. It was also noticed that after importing the resistance values into the model together with other parameters, the model was greatly improved and no cause for concern.
\end{abstract}

\section{Keywords}

Airways Resistance, Volumetric Efficiency, Friction Factor, Simulations

\section{Introduction}

The physical characteristics of the airways are essential to understand when determining the most effective airflow distribution, enhancing the volumetric effi- 
ciency and saving ventilation cost, because as mining activities advances, the production faces have progressed away from the main fans, which increased the resistance to airflow [1] [2] [3] [4]. Furthermore, airways physical characteristics such as length, area and roughness as well as obstacles (i.e. machines, conveyors or other equipment) determine the airflow characteristics and the resistance an airway presents to airflow. Hence, knowing these characteristics is essential for ventilation modelling as well as for long-term planning airflow requirements [5]. However, one of the essential characteristics to consider when determining the airway resistances is the friction factor $(k)$, which reliant on the geometrical physical characteristics of the airway, the mining approach, and the physical atmosphere of the mine [3] [4]. This resistance is definitely a function of the friction factor $(k)$ which collectively generates resistance to airflow. The existing accessible information at Rosh Pinah zinc mine is mainly focused on airflows, pressure drops as well as the thermal conditions of the airways. These values have been used for a long-time, with only some modifications in the case of Western Orefield by [6], who indicated that the mine has aggressively faced airflow distribution challenges. Thus, the challenge with these values without being tie-up with airway resistance provides insufficient information to address airflow distribution challenges [7].

Therefore, one study has extended this information taking into account the mining dynamic of the Western Orefield [2], establishing an essential simulation, but without specific values for airway resistances. In this study, airway resistances were determined for five levels at Rosh-Pinah underground zinc mine using continuous mining machines and the sub-level open stoping method. Once the airway resistances have been determined, a model was formulated in order to validate and simulate the results using VentSim software.

\section{Mine Background}

Rosh Pinah Zinc mine is located in the town of Rosh Pinah which is roughly 400 $\mathrm{km}$ southwest of Keetmanshop in Namibia. The mine was opened in 1969 to extract two major ores which are lead and Zinc. This subsurface operation has advanced over $480 \mathrm{~m}$ with western ore field being the dominant production zone. The ores are exploited using still and bench open stopping methods. The mine zones are separated into three orebodies predominantly, Eastern Orefield (EoF), Southern Orefield (SoF), and Western Orefield (WoF) as in Figure 1.

\section{Ventilation Circuit}

The design of main ventilation infrastructure of a mine considers a vital decision which is whether to connect the main fans to the up-cast shaft (exhausted system) or otherwise, to connect the main fans to the down-cast shaft-forcing system [7]. However, Rosh Pinah mine uses the exhausted ventilation system which is supplying approximately $150.1 \mathrm{~m}^{3} / \mathrm{s}$ through the declining access ramp linked to eight levels as illustrated in Figure 2. The intakes air is supplied through the 


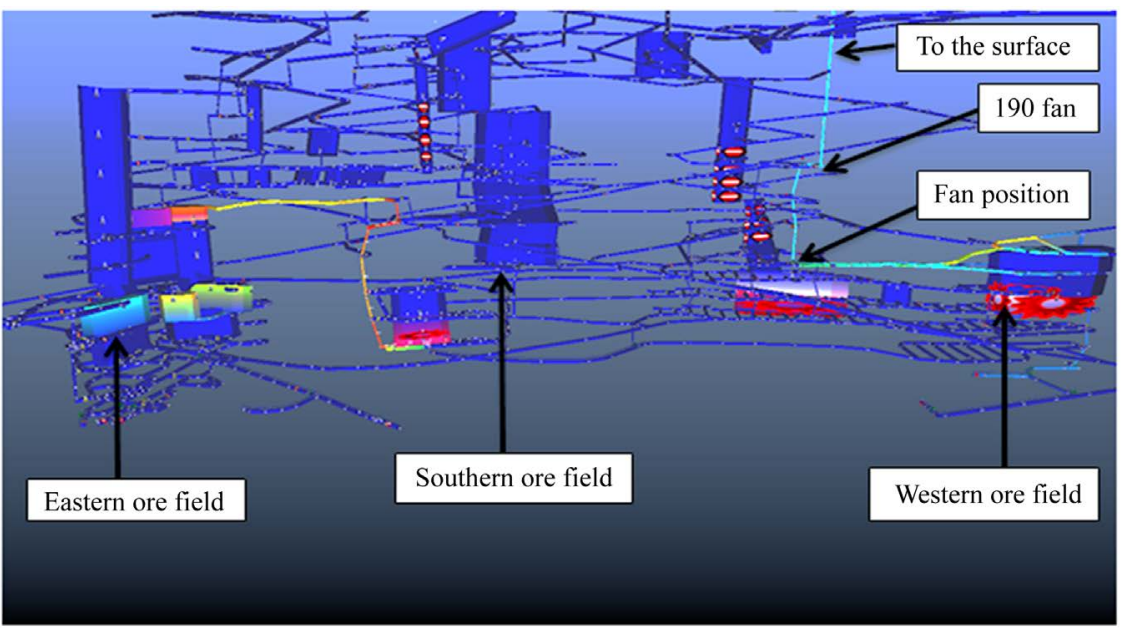

Figure 1. Layout of Orebodies zones at Rosh Pinah Zinc mine.

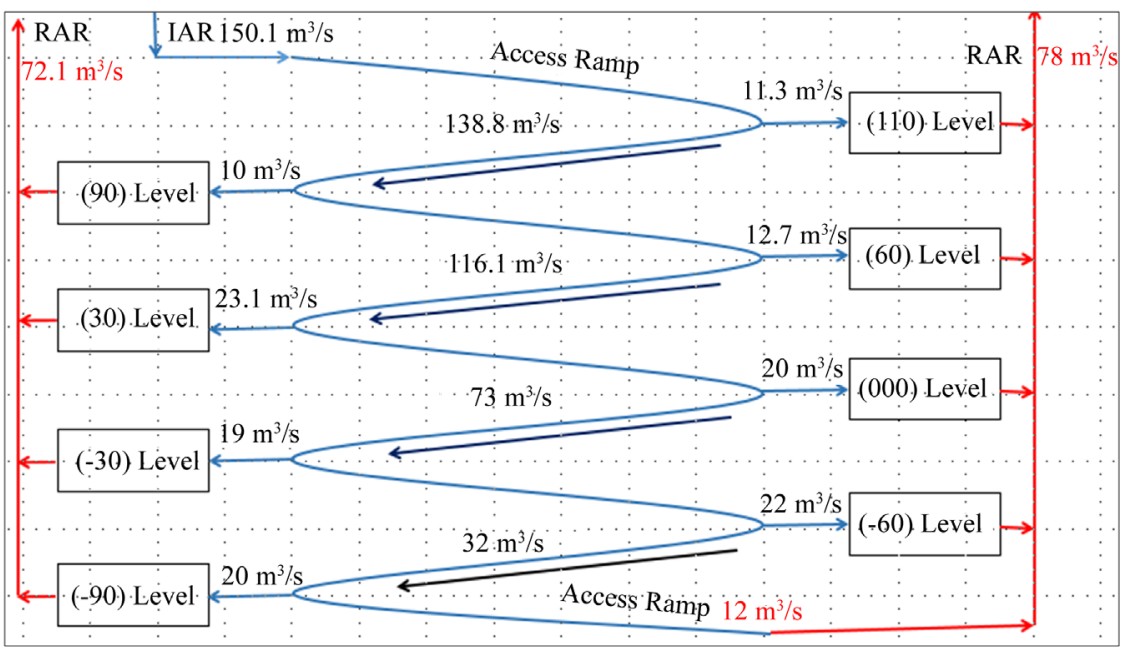

Figure 2. Ventilation circuit for Western Orefield.

decline adit while the exhaust air is reverted to the atmosphere by an exhaust main fan linked to the return raise. Western Orefield has a complex ventilation circuit requiring efficient usage and management of air control within the mine [2] [4] [8]. The deeper level of the mine ( -90$)$ is relatively hot and humid, which cause no great health concern. Western Orefield currently has two main exhaust fans installed at the top of the depleted stops, which are liable for removing contaminated air out of the stopes and out-side of the mine. However, this study proposed two more main exhaust fans to be installed at 90 level of another depleted stopes and five booster fans in order to improve airflow requirements. The Specifications and the place of these fans are detailed in Table 1.

\section{Data Collection and Methods}

Friction factors which are essential in the determination of the airways resistance require a data bank of the physical characteristics of the airways (Meyer, 1998 as referenced in [1]). Therefore, 32 (i.e. A-AG) branch points that stand for 
Table 1. Specifications of proposed main and booster fans for western Orefield.

\begin{tabular}{cccc}
\hline Fan type & Connection & Capacity & Place \\
\hline $2 \times$ J67 Airtech Davidson fans & Parallel & $0.214 \mathrm{kPa} 92.1 \mathrm{~m}^{3} / \mathrm{s}$ & Surface \\
$2 \times$ Donkin centrifugal main fans & Parallel & $0.200 \mathrm{kPa} 83.4 \mathrm{~m}^{3} / \mathrm{s}$ & 90 level \\
$1 \times$ Booster fan & Series & $0.191 \mathrm{kPa} 30.9 \mathrm{~m}^{3} / \mathrm{s}$ & 30 level \\
$1 \times$ Booster fan & Series & $0.199 \mathrm{kPa} 32.3 \mathrm{~m}^{3} / \mathrm{s}$ & 000 level \\
$1 \times$ Booster fan & Series & $0.200 \mathrm{kPa} 47.5 \mathrm{~m}^{3} / \mathrm{s}$ & -30 level \\
$1 \times$ Booster fan & Series & $0.205 \mathrm{kPa} 31.3 \mathrm{~m}^{3} / \mathrm{s}$ & -60 level \\
$1 \times$ Booster fan & Series & $0.209 \mathrm{kPa} 31.0 \mathrm{~m}^{3} / \mathrm{s}$ & -90 level
\end{tabular}

ventilation circuit have been selected to denote the airways and model conditions. After selecting essential branch points, all of them were marked with letters from A to AG. Nine measurements of height, width and roughness of airways which later were taken as a mean were carried out at an offset distance of $10 \mathrm{~m}$ apart at each branch point, using laser distance meter, and tape measure respectively. Moreover, mean air velocity at each branch point was also measured using rotating vane anemometer. Subsequently information such as obstacles, shapes and length of the branch point and directional deviations were also logged. The mean area, perimeter, hydraulic mean diameter, roughness, coefficient of friction and friction factors values were determined and categorised according to the five levels of the mine.

\section{Theoretical Equations}

The square law Equation (1) is the fundamental expression used to examine the airflow behaviour in underground mines [1] [7] which relates the theories of pressure, airflow, and resistance to the passage of air through an airway.

$$
\Delta P=R \times Q^{2} \quad(\mathrm{~Pa})
$$

where, $\Delta P$, is pressure drop $(\mathrm{Pa}), R$, is Atkinson's resistance $\left(\mathrm{Ns}^{2} / \mathrm{m}^{8}\right), Q$, is airflow $\left(\mathrm{m}^{3} / \mathrm{s}\right)$.

The similar expression was expressed in terms of resistance using the square law Equation (2) and in view of any deviation in air density inside the mine due to temperature factors [7].

$$
R_{b}=\frac{P}{Q^{2}}=k \cdot\left(L+L_{e q}\right) \frac{\operatorname{Per}}{A^{2}} \frac{\rho}{1.2}\left(\mathrm{~N} \cdot \mathrm{s}^{2} / \mathrm{m}^{2}\right)
$$

Furthermore, Von Karman's expression offers a link between the coefficient of friction and the friction factor from Atkinson's equation for turbulent flows.

$$
f=\frac{2 \cdot k}{\rho}=\frac{1}{4\left[2 \log _{10}\left(\frac{D_{h}}{e}\right)+1.14\right]^{2}} \text { (dimensionless) }
$$

where,

$D_{h}$ is hydraulic mean diameter of the airway $(\mathrm{m}), e$ is height of the roughening (m). 
According to [7], ventilation efficiency ( $V E)$ is expressed as:

$$
V E=(Q \text {, usefully employed }) /(\text { Total, } Q \text { through main fans }) \times 100(\%)
$$

The airways resistance was determined indirectly by measuring the airflow and the physical characteristics of the airways [7]. Thus, this study was based on the indirect technique.

\section{Results and Discussions}

Tables 2-6 indicatethe mean parameters obtained for each measuring point. These parameters are areas, perimeters (per), hydraulic mean diameters (Dh), roughness (e) and coefficient of friction (f) which are essential in the computation of airways resistance for each level. These values were computed using the data collected and the equations earlier detailed.

Table 2. Mean parameters used to compute airway resistance at 30 level.

\begin{tabular}{ccccccc}
\hline Measuring points & Area $(\mathrm{m})$ & Per $(\mathrm{m})$ & $\mathrm{Dh}(\mathrm{m})$ & $\mathrm{e}(\mathrm{m})$ & $\boldsymbol{f}$ & $\boldsymbol{k}\left(\mathrm{kg} / \mathrm{m}^{3}\right)$ \\
\hline A & 20.9 & 19.3 & 4.81 & 0.230 & 0.01749 & 0.00994 \\
B & 22.9 & 18.7 & 4.68 & 0.124 & 0.01353 & 0.00769 \\
C & 26.4 & 19.4 & 4.75 & 0.067 & 0.01064 & 0.00602 \\
D & 24.9 & 20.2 & 4.87 & 0.098 & 0.01218 & 0.00698 \\
E & 21.6 & 20.1 & 4.88 & 0.140 & 0.01399 & 0.00791 \\
F & 23.3 & 17.1 & 4.21 & 0.480 & 0.02731 & 0.01548 \\
Mean & & & & 0.190 & & \\
\hline
\end{tabular}

Table 3. Mean parameters used to compute airway resistance at 000 level.

\begin{tabular}{ccccccc}
\hline Measuring points & Area $(\mathrm{m})$ & Per $(\mathrm{m})$ & $\mathrm{Dh}(\mathrm{m})$ & $\mathrm{e}(\mathrm{m})$ & $f$ & $\boldsymbol{k}\left(\mathrm{kg} / \mathrm{m}^{3}\right)$ \\
\hline G & 23.2 & 21.4 & 5.35 & 0.140 & 0.01349 & 0.00762 \\
H & 22.8 & 18.2 & 4.52 & 0.185 & 0.01630 & 0.00921 \\
J & 22.4 & 20.0 & 4.76 & 0.503 & 0.02614 & 0.01502 \\
K & 20.7 & 19.8 & 4.72 & 0.125 & 0.01356 & 0.00757 \\
L & 25.1 & 18.8 & 4.62 & 0.196 & 0.01657 & 0.00945 \\
M & 26.3 & 17.6 & 4.32 & 0.160 & 0.01560 & 0.00881 \\
N & 25.4 & 18.4 & 4.55 & 0.150 & 0.01485 & 0.00831 \\
Mean & & & & 0.208 & & \\
\hline
\end{tabular}

Table 4. Mean parameters used to compute airway resistance at -30 level.

\begin{tabular}{ccccccc}
\hline Measuring points & Area $(\mathrm{m})$ & Per $(\mathrm{m})$ & Dh $(\mathrm{m})$ & $\mathrm{e}(\mathrm{m})$ & $\boldsymbol{f}$ & $\boldsymbol{k}\left(\mathrm{kg} / \mathrm{m}^{3}\right)$ \\
\hline O & 25.4 & 18.2 & 4.08 & 0.167 & 0.01628 & 0.00925 \\
P & 20.9 & 15.8 & 3.94 & 0.400 & 0.02557 & 0.01459 \\
Q & 22.7 & 17.8 & 4.39 & 0.175 & 0.01612 & 0.00919 \\
R & 22.4 & 16.0 & 3.98 & 0.205 & 0.01809 & 0.01021 \\
S & 19.0 & 20.5 & 4.94 & 0.340 & 0.02082 & 0.01162 \\
T & 19.5 & 20.2 & 4.82 & 0.280 & 0.01917 & 0.01089 \\
Mean & & & & $\mathbf{0 . 2 6 1}$ & & \\
\hline
\end{tabular}


Table 5. Mean parameters used to compute airway resistance at -60 level.

\begin{tabular}{ccccccc}
\hline Measuring points & Area $(\mathrm{m})$ & Per $(\mathrm{m})$ & Dh $(\mathrm{m})$ & $\mathrm{e}(\mathrm{m})$ & $\boldsymbol{f}$ & $\boldsymbol{k}\left(\mathrm{kg} / \mathrm{m}^{3}\right)$ \\
\hline U & 23.3 & 19.6 & 4.89 & 0.206 & 0.01649 & 0.00924 \\
V & 23.3 & 17.6 & 4.33 & 0.345 & 0.02244 & 0.01268 \\
W & 25.0 & 19.3 & 4.80 & 0.180 & 0.01569 & 0.00900 \\
X & 17.6 & 17.3 & 4.30 & 0.260 & 0.01954 & 0.01130 \\
Y & 30.4 & 19.0 & 4.60 & 0.290 & 0.01995 & 0.01154 \\
Z & 29.8 & 18.6 & 4.58 & 0.190 & 0.01640 & 0.00949 \\
Aa & 35.0 & 15.8 & 3.95 & 0.290 & 0.02151 & 0.01244 \\
Mean & & & & 0.252 & & \\
\hline
\end{tabular}

Table 6. Mean parameters used to compute airway resistance at -90 level.

\begin{tabular}{ccccccc}
\hline Measuring points & Area $(\mathrm{m})$ & Per $(\mathrm{m})$ & Dh $(\mathrm{m})$ & $\mathrm{e}(\mathrm{m})$ & $f$ & $\boldsymbol{k}\left(\mathrm{kg} / \mathrm{m}^{3}\right)$ \\
\hline $\mathrm{Ab}$ & 34.3 & 17.8 & 4.39 & 0.236 & 0.01846 & 0.01066 \\
$\mathrm{Ac}$ & 30.1 & 19.4 & 4.85 & 0.290 & 0.01942 & 0.01119 \\
$\mathrm{Ad}$ & 23.7 & 19.0 & 4.60 & 0.320 & 0.02095 & 0.01203 \\
$\mathrm{Ae}$ & 24.7 & 17.6 & 4.35 & 0.320 & 0.02154 & 0.01232 \\
$\mathrm{Af}$ & 26.8 & 19.7 & 4.57 & 0.290 & 0.02000 & 0.01136 \\
$\mathrm{Ag}$ & 25.6 & 20.4 & 5.07 & 0.425 & 0.02306 & 0.01295 \\
Mean & & & & 0.314 & & \\
\hline
\end{tabular}

\subsection{Comparison of Results}

Table 7 compares the mean roughness, friction factors and resistance for each level of the mine. It should be pointed out that, as the mine advances its production faces deeper, these values increases suddenly. Also, the variation in these values between the levels could be due to the excavation distance or lack of airway maintenance in each level. Furthermore, since there is no friction factors information concerning Rosh Pinah mine, the values obtained for each level were taken as a mean and compared with the current values published for coal, Potash and other metal mines.

In Table 8, Rosh Pinah mine friction factor value was determined by adding all individual mean friction factors in Table 7 and treated as single average value $\left(0.01039 \mathrm{~kg} / \mathrm{m}^{3}\right)$ of the mine. However, this value was compared with friction factors values $0.00762 \mathrm{~kg} / \mathrm{m}$ for Potash Mine and $0.01200 \mathrm{~kg} / \mathrm{m}$ metal mine publication respectively. The comparisons are expressed in terms of percentage for simplicity. As indicated in Table 8, there is an important difference in Potash mine and Rosh Pinah mine value, however, there is a significant correlation with McPherson value.

\subsection{Modelling and Simulation}

The airflow requirement at the production faces was designed using mine 
Table 7. Mean roughness, resistance and standard deviation of Rosh Pinah mine.

\begin{tabular}{cccc}
\hline Levels & $e(\mathrm{~m})$ & $k\left(\mathrm{~kg} / \mathrm{m}^{3}\right)$ & $R\left(\mathrm{Ns}^{2} / \mathrm{m}^{8}\right)$ \\
\hline 30 & 0.190 & 0.009003 & 0.15901 \\
000 & 0.208 & 0.009427 & 0.23193 \\
-30 & 0.261 & 0.010958 & 0.28948 \\
-60 & 0.252 & 0.010812 & 0.33798 \\
-90 & 0.314 & 0.011751 & 0.58294 \\
Mean & $\mathbf{0 . 2 4 5}$ & $\mathbf{0 . 0 1 0 3 9 0}$ & $\mathbf{0 . 3 2 0 2 7}$ \\
Standard deviation & $\mathbf{0 . 0 4 9}$ & $\mathbf{0 . 0 0 1 1 4 0}$ & $\mathbf{0 . 1 6 1 2 9}$ \\
\hline
\end{tabular}

Table 8. Percentage variation between friction factors values obtained and published.

\begin{tabular}{cccc}
\hline \multirow{2}{*}{ Airway type } & $\begin{array}{c}\text { Rosh Pinah mean } \\
\text { value } \mathrm{k}\left(\mathrm{kg} / \mathrm{m}^{3}\right)\end{array}$ & Potash mine value & McPherson \\
\cline { 3 - 4 } & & -26.7 & 15.5 \\
\hline $\begin{array}{c}\text { Rectangular airway, } \\
\text { some irregularities }\end{array}$ & 0.01039 & & Variation (\%) \\
\hline
\end{tabular}

machinery and personnel airflow requirement based to the mine ventilation standards of Namibia [9]. The pessimistic approach (worst case scenario) was used and $28.3 \mathrm{~m}^{3} / \mathrm{s}$ was achieved. Prior to the model simulation, the existing ventilation model of Western Orefield was updated with the developed airway resistance and the new booster fans circled in Figure 3 by importing lengthy level plans (survey plans) as DXF files. The lengthy branches were drawn and modified in VentSim. The model was then simulated with the airway resistance values, using the six possible options and different control methods. The following six options were considered for simulation.

Option 1: original model (Base case).

Rosh Pinah mine has employed three regulators in combination with one airlock. Leakage at Rosh Pinah is one of the key challenges, as useful airflow short circuit through the return airway. This was an essential case, whereby the original model was assessed on its current state. The airflow measured within levels is shown in Table 9. Prior to simulation, the existing Rosh Pinah mine model was validated as shown in Figure 4. The characteristics curve for the existing J67 airtech Davidson main fans indicate that the fans are running at $850 \mathrm{rpm}$ at a shaft power of $440 \mathrm{~kW}$. Twin J67 airtech Davidson main fans are installed at 190 level exhausting about $150.1 \mathrm{~m}^{3} / \mathrm{s}$ of airflow at a $1.73 \mathrm{kPa}$. The resistance values were assigned to airways, brattice cloth (temporary stopping) and brick wall stoppings (permanent stoppings). A simulation without considering the sealing off stoppings and model modification was run; Based on the designed airflow requirements, it is evident that all levels have not satisfied minimum airflow demand and no airflow redundancy measured. However, the leakage percentage for all the levels has exceeded the $20 \%$ leakage allowable critically.

The model has two main fans connected in parallel (J67 Airtech Davidson 


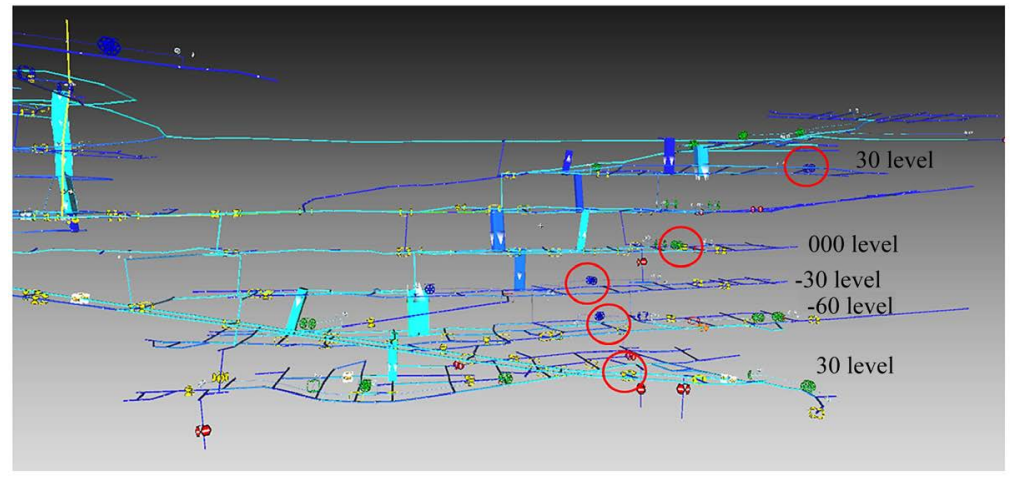

Figure 3. New ventilation model and installed booster fans locations.

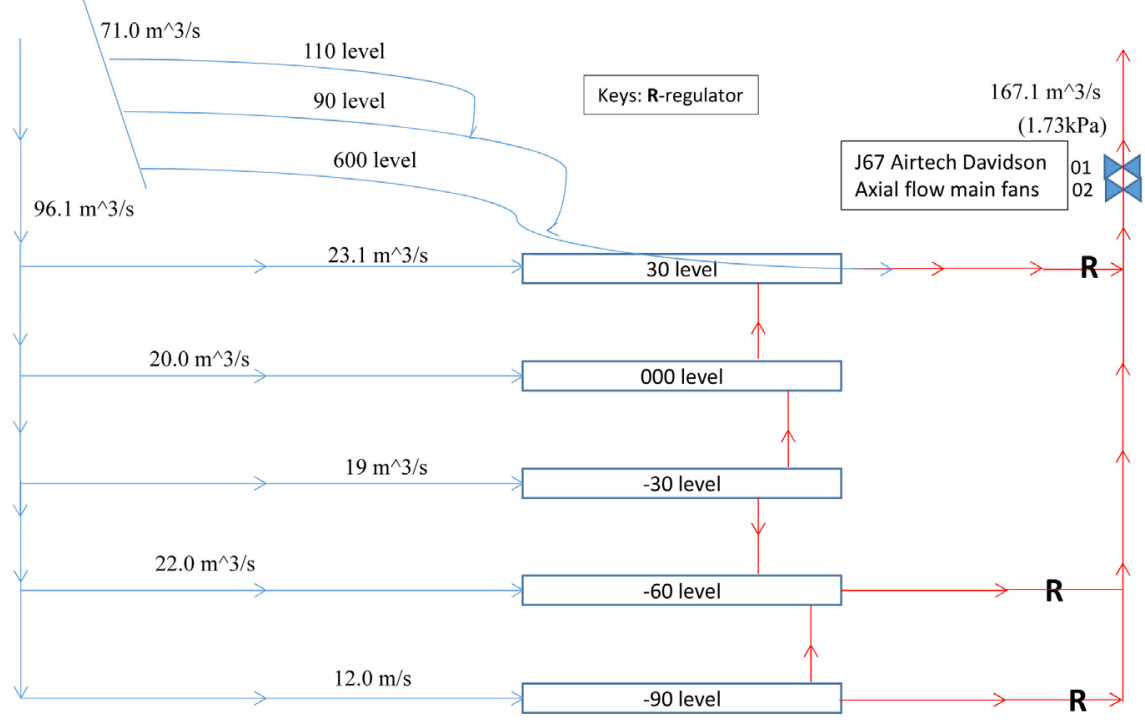

Figure 4. Existing ventilation setup at Rosh Pinah mine.

Table 9. Comparisons of airflow.

\begin{tabular}{ccccc}
\hline Levels & $\begin{array}{c}\text { Airway resistance } \\
\left(\mathrm{Ns}^{2} / \mathrm{m}^{8}\right)\end{array}$ & $\begin{array}{c}\text { Measured airflow } \\
\left(\mathrm{m}^{3} / \mathrm{s}\right)\end{array}$ & $\begin{array}{c}\text { Designed airflow } \\
\left(\mathrm{m}^{3} / \mathrm{s}\right)\end{array}$ & $\begin{array}{c}\text { Simulated airflow } \\
\left(\mathrm{m}^{3} / \mathrm{s}\right)\end{array}$ \\
\hline 30 & 0.15901 & 23.1 & 28.3 & 30.9 \\
000 & 0.23193 & 20.0 & 28.3 & 32.3 \\
-30 & 0.28948 & 19.0 & 28.3 & 47.5 \\
-60 & 0.33798 & 22.0 & 28.3 & 31.3 \\
-90 & 0.58294 & 12.0 & 28.3 & 30.0 \\
\hline
\end{tabular}

Axial flow fans N0.1 \& N0.2) The J67 Airtech Davidson Axial flow fans can operate at 51.5 and $83.6 \mathrm{~m}^{3} / \mathrm{s}$ at 0.214 to $1.733 \mathrm{kPa}$ respectively. Moreover, these fans supplies $167.1 \mathrm{~m}^{3} / \mathrm{s}$ to western Orefield. Therefore, the current ventilation set-up Figure 4, does not meet the ventilation demand because of the leakage through old permanent and temporary stoppings.

Option 2: widen return shaft from level 30 to surface. 
In this option, a model that incorporated a widened existing return shaft advanced from level 30 to surface for a distance of $340 \mathrm{~m}$ was developed. The exhaust shaft was constructed with the drive dimension of $4.5 \mathrm{~m}$ height kept constant and width of drives increased from $5 \mathrm{~m}$ to $9 \mathrm{~m}$. The return shaft was increased by $4 \mathrm{~m}$. A ventilation raise between Level-60 and -90 was not practical to seal it off during simulation because of an outstanding wall construction at level-60 B5-pump areas. However, all the other high leakage potentials were sealed off and permanent stoppings assigned a resistance value of $5000 \mathrm{Ns}^{2} / \mathrm{m}^{8}$. The resistance of the regulators were reduced and located depending on the airways resistance and airflow requirements. The model is illustrated in Figure 3.

The characteristic curves for the Donkin centrifugal and J67 Airtech Davidson fans indicated that they could operate at very high pressures, but as their operating pressures increases, the airflow of the fans would suddenly decrease. In order to achieve the desired airflow, respective levels have been assigned computed resistance, and with no regulators. The two Donkin centrifugal fans were used, operating at $125.2 \mathrm{~m}^{3} / \mathrm{s}(1.495 \mathrm{kPa})$, however, the J67 Airtech Davidson fans could operate at a slightly higher pressure than the Donkin centrifugal fans. The J67 Airtech Davidson fans could operate at its maximum (1.535 kPa), however it appeared that $6.2 \mathrm{~m}^{3} / \mathrm{s}$ was the greatest amount of airflow that could be carried to -90 levels which is the lower section of the mine. On the other hand, air leakage for this option is approximately $90 \%$ on average, which means only about $10 \%$ potentially reaches the production faces. $50 \%$ of airflow entered 30 levels for two reasons, low resistance and shorter excavation distance.

Option 3: Install regulators and reduce main fans speed.

In this option, five regulators were installed; one on each level to ensure equivalent airflow is delivered to each level. However, main fans speed of both the Donkin centrifugal and J67 Airtech Davidson fans were reduced from an operating point of $125.2 \mathrm{~m}^{3} / \mathrm{s}(1.495 \mathrm{kPa})$ to $94.6 \mathrm{~m}^{3} / \mathrm{s}(0.550 \mathrm{kPa})$ and $140.2 \mathrm{~m}^{3} / \mathrm{s}$ $(1.535 \mathrm{kPa})$ to $101.5 \mathrm{~m}^{3} / \mathrm{s}(0.570 \mathrm{kPa})$ respectively. The leakages were well below $20 \%$ allowable and the volumetric efficiency averaging to about $90 \%$ for each level has been improved significantly. Moreover, the adjustments made in this option were based on option 1 and option 2.

Option 4: Combine regulators and booster fans.

This option considered the usage of booster fans and regulators. However, regulators were uninstalled on level -60 , and -90 , which are levels of high resistance and replaced with two booster fans. It was hypothesized that, option 3 airflows would be the original minimum air demand and could not be further reduced. In this option however, leakage have been maintained well below $20 \%$. Also, the volumetric efficiency of the levels was maintained extremely well to meet production faces minimum airflow demand. However, the difficulty of this option is that in case of the booster fan stoppage, this allow the accumulation of gasses which may be hazardous to the people and the entire mine itself [7]. The benefits of booster fans are that, they improve the air flow in the mine in the area where it is difficult to ventilate, increase flow rates in high-resistance circuits, 
and, reduce the pressure requirements of the main fan.

Option 5: Install each level with a booster fan connected in series.

In this scenario, all regulators were removed, and five booster fans were installed one in each level as shown in Figure 3. However, booster fans operating points are shown in Table 1. This model has maintained minimum air demand. The Levels airways resistances are shown in Table 7 and Table 9. Although, the benefits are the same as of option 4 , booster fans can reduce the ability to control recirculation of air in underground mines.

Option 6: Booster fans sharing more duty.

In this scenario, an adjustment has been made on the booster fans based on option 5. However, the booster fans were considered to share more duty and assumed to have the same efficiency as the main fans. By sharing the booster fans more work with the main fans, the airflow regulatory standard was achieved. All the production faces met the regulatory requirements. The airflow that entered the entire mine was $260.1 \mathrm{~m}^{3} / \mathrm{s}$. The airflow at the production face at all the levels went up significantly with about $90 \%$ volumetric efficiency.

\subsection{Volumetric Efficiency and Airflow Comparison}

The airflows values in Table 9 were achieved by using the given input data from the pressure-quantity survey methods. However, three airflow types predominantly measured, designed and simulated were determined through the following methods:

\subsubsection{Measured Airflow}

From the given input data stated in the methodology, the air velocities were first determined by dividing the distance covered by the rotating vane anemometer. The velocities were corrected by adding the correction factor (0.8) of the anemometer to achieve the actual velocity.

However, measured airflow was calculated using Equation (5) according to [7] below:

$$
Q=u \times A\left(\mathrm{~m}^{3} / \mathrm{s}\right)
$$

where, $Q\left(\mathrm{~m}^{3} / \mathrm{s}\right)$ is the air quantity, $u(\mathrm{~m} / \mathrm{s})$ is velocity and $A\left(\mathrm{~m}^{2}\right)$ is the cross-sectional area of the airways shown in Tables 2-6.

\subsubsection{Designed Airflow}

Ventilation demand was determined by banking information such as the number of miners working per shift including contractors, types of equipment employed and the size of the airways or working faces. The airflow requirements to dilute the diesel particulate matter, fresh air demand for mine workers and working faces were computed using Equations (6)-(8) respectively.

$$
\begin{aligned}
& Q e=\text { number of equiment } \times \text { rated power of engine } \times D f \\
& Q w s=\text { number of miners } \times \text { minimum requirement } / \text { miner }
\end{aligned}
$$

$Q f=$ cross-sectional area $\times$ minimum airflow requirement per square meter 
Table 10. Comparison of airflow variation.

\begin{tabular}{ccc}
\hline Levels & $\begin{array}{c}\text { Measured vs Designed airflow variation } \\
\left(\mathrm{m}^{3} / \mathrm{s}\right)\end{array}$ & $\begin{array}{c}\text { Simulated vs Designed airflow variation } \\
\left(\mathrm{m}^{3} / \mathrm{s}\right)\end{array}$ \\
\hline 30 & -5.2 & 2.6 \\
000 & -8.3 & 4.0 \\
-30 & -9.3 & 19.2 \\
-60 & -6.3 & 3.0 \\
-90 & -16.3 & 1.7 \\
\hline
\end{tabular}

where, $Q e\left(\mathrm{~m}^{3} / \mathrm{s}\right)$ is the air demand for equipment, $D f$ is the dilution factor (i.e. $0.0633 \mathrm{~m}^{3} / \mathrm{s}$ per kilowatts), Qws $\left(\mathrm{m}^{3} / \mathrm{s}\right)$ is the miners airflow requirement where by minimum airflow per miner is $0.0033 \mathrm{~m}^{3} / \mathrm{s}, Q f\left(\mathrm{~m}^{3} / \mathrm{s}\right)$ is the air demand for the working faces whereby $0.015 \mathrm{~m}^{3} / \mathrm{s}$ is the minimum airflow requirement per square meter.

The pessimistic approach was used to choose the air demand needed at the working faces by taking the highest airflow achieved by one of Equations (6)-(8). As it can be seen in Table 9, that $28.3 \mathrm{~m}^{3} / \mathrm{s}$ was the highest designed air demand.

\subsubsection{Simulated Airflow}

By replacing three regulators shown in Figure 4 with five booster fans shown in Figure 3 the air demand as per regulatory standard was achieved as discussed in the design option 3, 4, 5, and 6. However, all the levels met the air demand. The airflows that entered the levels are shown in Table 9 with -30 level airflow went up to $47.5 \mathrm{~m}^{3} / \mathrm{s}$. The mean airflow reaching the production faces in the simulated model was $34.4 \mathrm{~m}^{3} / \mathrm{s}$ compared to the mean airflow of $19.2 \mathrm{~m}^{3} / \mathrm{s}$ reaching the working faces in the field. The volumetric efficiency was therefore improved from $29.3 \%$ to $68.3 \%$.

Comparisons of airflow variation results revealed that -30 level received more airflow in simulation compared to the measured airflow in the same level. Furthermore, -90 level is yet at a developing stage, the airflow measured was 12.0 $\mathrm{m}^{3} / \mathrm{s}$ compared to $30.0 \mathrm{~m}^{3} / \mathrm{s}$ simulated as detailed in Table 9 and Table 10 respectively. The most realistic solution to increase the volumetric efficiency of the mine however would be to determine airway resistance in all the levels.

\section{Conclusion}

Airways resistance results revealed that as the mine advances deeper the resistance of mine increases [7]. Since Western Orefield is still advancing deeper (480 $\mathrm{m})$, the airway resistance determined in the levels were showing a sudden increase with airflow measured being below the designed minimum requirement. The volumetric efficiency of the mine however, was improved from $29.3 \%$ to $68.3 \%$. It is therefore significant to note that the most possible solution to increase the airflow at Rosh Pinah mine is to determine the airway resistance in the levels which would help to understand airflow behaviour. However, this 
study achieved a framework which would be used for future studies in determining airways resistance and the mine system curves to visualise individual level at a various flow rate which would help in the decision making for fan selections. The study would also encourage ventilation planners to use field data to determine mines system curves which is a primary step for ventilation optimisation.

\section{Recommendation}

In this study it was therefore recommended that subsurface zinc mine should develop combined ventilation survey database for various projects that are undertaken, to assist in data bank for future researches.

\section{Acknowledgements}

The author acknowledges the management and all the workers who assisted in one way or another in collection of data for this research.

\section{Conflicts of Interest}

The authors declare no conflicts of interest regarding the publication of this paper.

\section{References}

[1] Bascompta, M., Sanmiquel, L., Anticoi, H.F. and Oliva, J. (2019) Ventilation Friction Factor Determination and Comparison: Two Case Studies of Potash Mining. Journal of the Southern African Institute of Mining and Metallurgy, 119, 865-870. https://doi.org/10.17159/2411-9717/707/2019

[2] Develo, E., Pillalamarry, M. and Garab, E. (2016) Improving the Ventilation System at Zinc Mine. Journal of the Southern African Institute of Mining and Metallurgy, 116, 301-305. https://doi.org/10.17159/2411-9717/2016/v116n4a1

[3] Massanés, M.B., Pera, L.S. and Moncunill, J.O. (2014) Determination of the Friction Factors in Potash Mines. Journal of Mining Science, 50, 953-958. https://doi.org/10.1134/S1062739114050159

[4] Prosser, B.S., Stinnette, J.D. and Paredes, J. (2002) Ventilation Optimization at the La Camorra Mine. CRC Press, Boca Raton, 61-74.

[5] Kocsis, K.-C. (2009) New Ventilation Design Criteria for Underground Metal Mines Based upon the Life-Cycle Airflow Demand Schedule. PhD. Thesis, The University of British Columbia, Vancouver.

[6] Gabriel, U. (2020) Ventilation Systems of Rosh Pinah Mine. 1, 2-5.

[7] McPherson, M.J. (1993) Subsurface Ventilation and Environmental Engineering. Springer Science \& Business Media, Berlin, 92-350.

https://doi.org/10.1007/978-94-011-1550-6

[8] Pritchard, C. (2010) Methods to Improve Efficiency of Mine Ventilation Systems. National Institute for Occupational Safety and Health, Spokane Research Laboratory (SRL), 1-5.

[9] Ministry of Mines and Energy (1992) Mine Health and Safety Regulations, 10th Draft. Windhoek. 